\title{
Lg attenuation in northeast China using NECESSArray data
}

\author{
Nishath R. Ranasinghe, ${ }^{1}$ Andrea C. Gallegos, ${ }^{1}$ Andrea R. Trujillo, ${ }^{1,2}$ \\ Alexander R. Blanchette, ${ }^{1}$ Eric A. Sandvol, ${ }^{3}$ James Ni, ${ }^{1}$ Thomas M. Hearn, ${ }^{1}$ \\ Youcai Tang, ${ }^{4,5}$ Stephen P. Grand, ${ }^{4}$ Fenglin Niu, ${ }^{5,6}$ Yongshun J. Chen, ${ }^{7}$ Jieyuan Ning, ${ }^{7}$ \\ Hitoshi Kawakatsu, ${ }^{8}$ Satoru Tanaka ${ }^{9}$ and Masayuki Obayashi ${ }^{9}$ \\ ${ }^{1}$ Department of Physics, New Mexico State University, Las Cruces, NM 88001, USA. E-mail: nrana001@nmsu.edu \\ ${ }^{2}$ Apache Corporation, 303, Veterans Airpark Lane, \#600, Midland, TX 79705, USA \\ ${ }^{3}$ Department of Geological Sciences, University of Missouri, 101 Geology Bldg., Columbia, MO 65211, USA \\ ${ }^{4}$ Jackson School of Geosciences, The University of Texas at Austin, Austin, TX 78712, USA \\ ${ }^{5}$ State Key Laboratory of Petroleum Resource and Prospecting and Unconventional Natural Gas Institute, China University of Petroleum, \\ Beijing 102249, China \\ ${ }^{6}$ Department of Earth Science, MS-126, Rice University, Houston, TX 77005, USA \\ ${ }^{7}$ Institute of Theoretical and Applied Geophysics, SESS, Peking University, Beijing, China \\ ${ }^{8}$ Earthquake Research Institute, The University of Tokyo, Tokyo, Japan \\ ${ }^{9}$ Institute for Frontier Research on Earth and Evolution, Japan Agency for Marine-Earth Science and Technology, Yokosuka, Japan
}

Accepted 2014 September 24. Received 2014 September 23; in original form 2013 November 5

\begin{abstract}
S UMMAR Y
The 127 station NorthEast China Extended SeiSmic Array (NECESSArray) provides large quantities of high quality seismic data in northeast China that allow us to resolve lateral variations of $\operatorname{Lg} Q$ or crustal attenuation at $1 \mathrm{~Hz}\left(Q_{0}\right)$ to $2.0^{\circ}$ or greater. Using the reverse two-station/event method with $11642 \mathrm{Lg}$ path-amplitudes from 78 crustal earthquakes, we obtain a 2-D tomographic image of $\operatorname{Lg} Q_{0}$ with values ranging from $\sim 50$ to 1400 . A high degree of detail in the lateral variation of $\mathrm{Lg}$ attenuation is revealed in our tomographic image. High $Q_{\mathrm{o}}$ regions are found in the Great Xing'an, Lesser Xing'an and Songen-Zhangguangcai Ranges. Low $Q_{\mathrm{o}}$ regions are observed in the Songliao, Sanjiang and Erlian Basins. The lowest $Q_{\mathrm{o}}$ is found near the Wudalianchi volcanic field and other Quaternary volcanic fields, the southern Songliao Basin, the western edge of the Erlian Basin and the Sanjiang Basin. Low

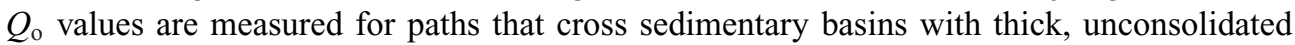
sediments. Most of the high Lg attenuation in the Songliao Basin correlates reasonably well with low crustal Rayleigh wave phase velocity anomalies. The highest attenuating regions also correlate well with regions of Holocene volcanism.
\end{abstract}

Key words: Tomography; Heat flow; Earthquake ground motions; Seismicity and tectonics; Guided waves; Seismic attenuation; Seismic tomography.

\section{INTRODUCTION}

The $\mathrm{Lg}$ wave is the most prominent high frequency $(f>0.5 \mathrm{~Hz})$ regional phase observed at regional distances. It has a group velocity of about $3.5 \mathrm{~km} \mathrm{~s}^{-1}$ in northeast China and can be modelled as the sum of higher mode surface waves (Oliver et al. 1955; Knopoff et al. 1973; Herrmann \& Kijko 1983) or as many supercritically reflected crustal $S$ waves (e.g. Bouchon 1982). This wave only propagates efficiently over continental paths and can be seen at distances up to $30^{\circ}$ in the Canadian Shield (Hasegawa 1985). The study of Lg wave attenuation has often been used for characterizing crustal structure since the sensitivity of the $\mathrm{Lg}$ wave to crustal properties makes it an important tool in better understanding the underlying causes of seismic anomalies in the crust (Ruzaikin et al. 1977; Ni \& Barazangi 1983; Xie \& Mitchell 1990; McNamara et al. 1996; Xie 2002; Zor et al. 2007; Phillips \& Stead 2008; Zhao et al. 2010; Bao et al. 2012). Lg attenuation is also an important factor in determining seismic hazard since the large amplitude of the $\mathrm{Lg}$ wave is capable of causing structural damage at regional distances (Campillo et al. 1989).

Early efforts to map crustal attenuation relied on the temporal decay rate of the Lg coda (e.g. Singh \& Herrmann 1983). In these studies source effects were model dependent and site effects, which are due to the near surface effect of sediments and the focusing and defocusing of the seismic waves, were omitted. Furthermore, efforts at understanding $\mathrm{Lg}$ attenuation have been restricted to modelling it as if only geometric spreading and attenuation affect the amplitude, while in reality, the $\mathrm{Lg}$ wave train is much more complicated. We contend that spreading and attenuation are the two primary factors affecting Lg spectral amplitude at regional distances. 
Indeed, synthetic modelling of Lg by Yang (2002) bears this out and we do not attempt more detailed modelling. Two approaches have lately been used to model the $\mathrm{Lg}$ amplitude. For example, Phillips \& Stead (2008) directly inverted for the source, path and site effects using a 2-D inversion to produce an Lg attenuation map of the western United States. Bao et al. (2011) used an improved Reversed Two-station/event Method (RTM) originally developed by Chun et al. (1987) to map regional Lg attenuation in the eastern Tibetan Plateau. The RTM removes the source term and site effects by dividing out these terms (Bao et al. 2011). We have chosen to implement the RTM in NE China using data collected by the 127 station NECESSArray. A prior Lg attenuation study by Zhao et al. (2010) used 20 stations and thus was only able to resolve the attenuation of broad geographical features. With the use of extensive data our study has greatly improved the resolution and smaller geological features can now be discerned.

In what follows, we discuss the geology and tectonics of NE China and the data and method used to model $\mathrm{Lg}$ attenuation. We performed our study using the RTM, which allows us to model Lg attenuation within NE China. Finally, we address anomalies revealed in the Lg tomography image and their relationship with geology, physical parameters of the crust and how our study compares with other studies in NE China. Our results demonstrate Lg attenuation in NE China is mainly due to the combined effects of unconsolidated sediments and Quaternary tectonics.

\section{GEOLOGY AND TECTONICS IN NORTHEAST CHINA}

NE China is a geologically complex area characterized by widespread Phanerozoic granitic rocks, Upper Mesozoic and Cenozoic volcanic rocks and sedimentary basins (Fig. 1). Granitic rocks cover at least 50 per cent of the area in mountainous regions with volcanic rocks forming most of the rest. The major basins are the Songliao, Hailar, Erlian and Sanjiang Basins. They are often deep and filled with rich, organic sediments. NE China is composed of fragments of small Archean blocks, Proterozoic blocks and intervening subduction complexes that were amalgamated before the Late Permian and then sutured onto the North China Block (NCB, also known as the Sino-Korean Craton) during the Late Triassic ( $224 \mathrm{Ma}$ ). The accreted NE China block, also known as the Central Asian Orogenic Belt, subsequently collided with the Siberian plate upon the closure of the Mongol-Okhotsk Ocean in the Late Jurassic (e.g. Sengör et al. 1993; Windley et al. 2007; Zhou et al. 2012; Zhou \& Wilde 2012).

Throughout much of the Mesozoic the tectonics of NE China were dominated by subduction of the Palaeo-Pacific oceanic plate from the east and the Mongol-Okhotsk oceanic plate from the north (e.g. Zhang et al. 2010; Li et al. 2012; Sun et al. 2012; Kiminami \& Imaoka 2013). These subduction episodes produced subduction related volcanic rocks and granitoids over hundreds of millions of years that are widespread in the Great Xing'an Range. In the late Mesozoic the Palaeo-Pacific subduction and slab rollback underneath NE China controlled much of the volcanism. Mantle upwelling associated with slab rollback and backarc return flow initiated the Songliao Basin, a series of interconnected half-grabens, at about $157 \mathrm{Ma}$ (e.g. Zhang et al. 2010; Trujillo 2013). In many ways the tectonics of NE China during the late Mesozoic is reminiscent of the tectonics of western North America during the Cenozoic (Trujillo 2013).

The Cenozoic tectonics of NE China were affected by the subduction of the Pacific Plate and the opening of the Sea of Japan. Intraplate alkaline volcanism occurred within the Songliao Basin in the early Cenozoic (Liu et al. 2001), while Oligocene and younger volcanism was distributed to the east and north of the Songliao

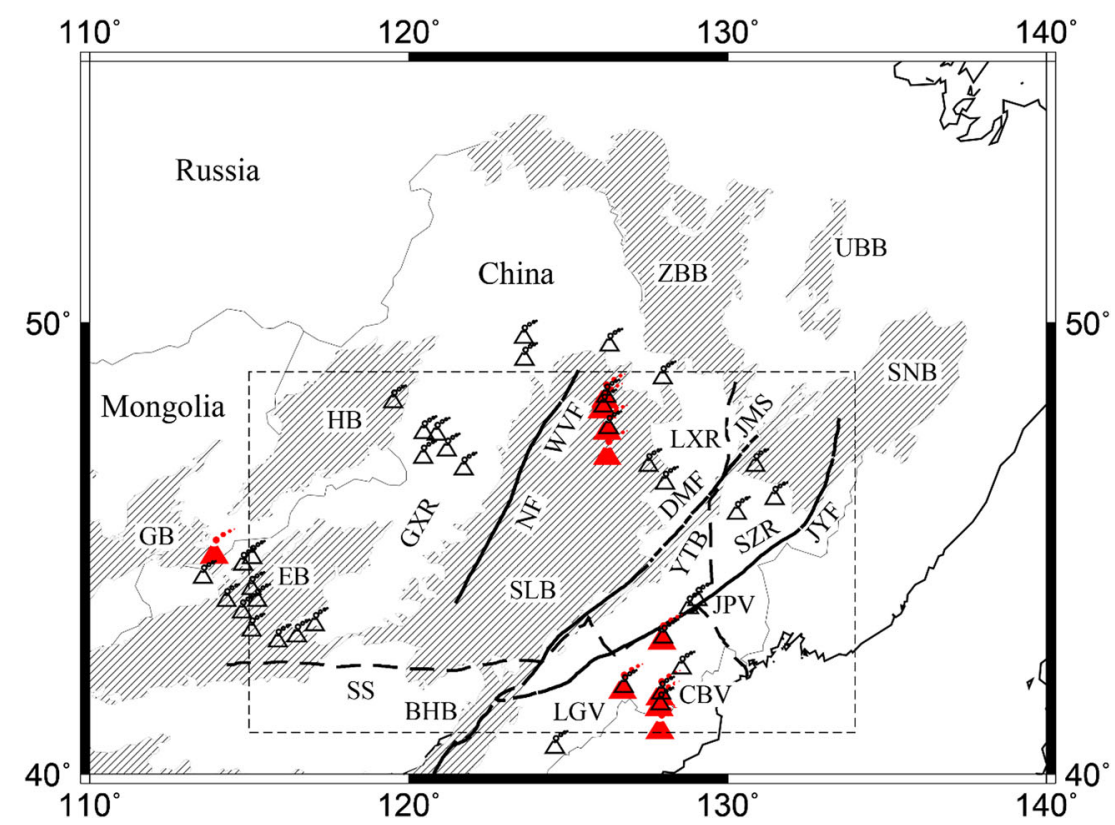

Figure 1. Tectonic map of NE China. Black lines are active faults and dotted black lines are Late Triassic sutures (after Zhou et al. 2012). Red triangles represent volcanoes of Holocene age and open triangles represent volcanoes of Pleistocene age. The hatched (diagonal lines) regions are sedimentary basins formed during Late Jurassic to Cretaceous times. Abbreviations on the maps are: GXR (Great Xing'an Range), LXR (Lesser Xing'an Range), SZR (SongenZhangguangcai Range), EB (Erlian Basin), GB (Gobi Basin), HB (Hailar Basin), SLB (Songliao Basin), ZBB (Zeya-Bureya Basin), UBB (Upper Bureya Basin), SNB (Sanjiang Basin), YTB (Yitong Basin), BHB (Bohai Basin), JMS (Jiayin-Mudanjiang Suture), SS (Suolon Suture), NF (Nenjiang Fault), DMF (Dunhua-Mishan Fault), JYF (Jiamusi-Yitong Fault), WVF (Wudalianchi Volcanic Field), JPV (Jingpuhi Volcanic Field), CBV (Changbaishan Volcanic Field) and LGV (Longgan Group of Volcanoes). 


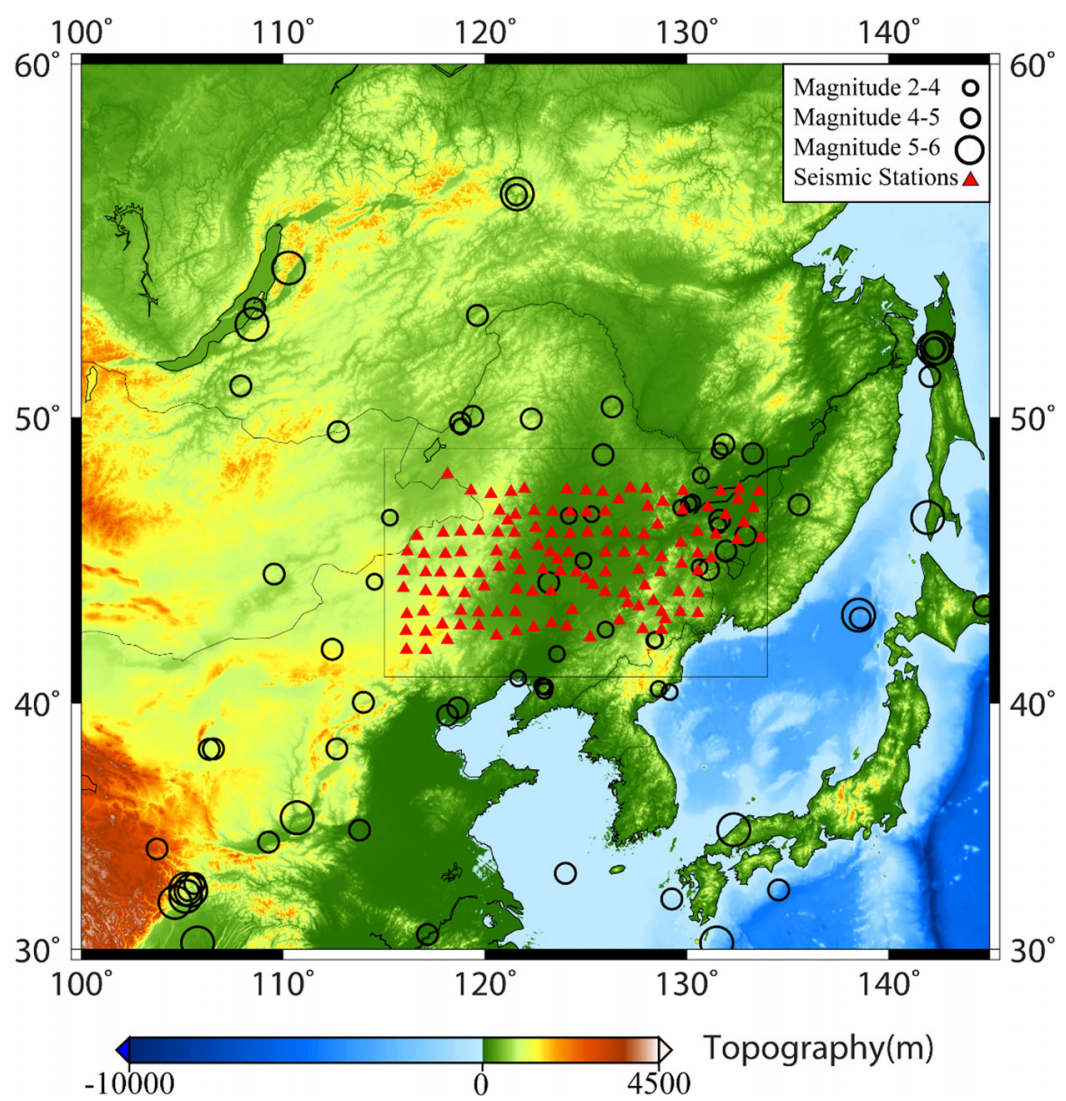

Figure 2. A map of the study region showing topography and the locations of 78 crustal events. Red triangles represent the locations of 127 NECESSArray stations.

Basin and to the southwest of the Great Xing'an Range (Liu et al. 2001). The present tectonics of NE China are characterized by E-W compression, right lateral strike-slip faulting on major NNEstriking faults and abundant intraplate volcanoes distributed around the Songliao Basin.

\section{DATA AND METHOD}

The data used in this study are collected by the 127 station NECESSArray (Fig. 2) from 2009 September 12 to 2011 August 19. This study uses 78 events (see Appendix) ranging from 2.5 to 6.0 in magnitude (Fig. 2). All events are located at $40 \mathrm{~km}$ or less in depth. Epicentral distances are limited to a minimum of $2.5^{\circ}$ and a maximum of $20^{\circ}$. These limits were used because $\mathrm{Lg}$ does not form at distances less than about $2.5^{\circ}$ and $\mathrm{Lg}$ becomes quite weak at distances greater than $20^{\circ}$.

The $\mathrm{Lg}$ waves show an increase in their maximum amplitude when the ray paths cross the Songliao Basin (Figs 3-5). Fig. 3 illustrates the spatial distribution of the theoretical ray paths along the radial directions, the location of the seismic stations and the location of two earthquakes that demonstrate wave amplification behaviour. An example of this amplification is shown in Fig. 4, which illustrates seismograms generated by an event that took place on 2011 July 16 near Lake Baikal. Station NE78, located in the Songliao Basin, recorded a half-maximum amplitude of $17451 \mathrm{~nm}$ while station NE77, located outside of the basin, recorded a halfmaximum amplitude of $8882 \mathrm{~nm}$ despite the fact that it is closer to the earthquake than station NE78. Station NE78 shows twice the amplitude of station NE77, even though it is further away from the source. The same near station site effects are generated by an earthquake that occurred on 2010 July 30 in Eastern Mongolia (Fig. 5). The amplitudes recorded by stations NE45, NE55 and NE56 within the basin are larger than the amplitude recorded by station NE75, which is located closer to the source and outside the basin.

The amplification of seismic waves can be caused by several factors. These factors are discussed in a study by Pratt et al. (2003). Low impedance in the top sedimentary layer of the basin relative to lower layers results in an increase in amplitude and resonances, which further contribute to the increase in Lg amplitude. Focusing caused by the basin or deeper structures can also contribute to the increase in $\mathrm{Lg}$ amplitude within the basin. Moreover, reflections from the side of the basin may constructively interfere with direct arrivals within the basin. According to Pratt et al. (2003) these last two effects are not as strong as the resonance effect caused by impedance contrast. In order to remove the site effect we use the RTM method.

The RTM method has the advantage that the site responses are completely removed since the site response for all the events recorded by a particular station is assumed to be identical and thus cancels out when the amplitude ratios are divided. The main disadvantage of this method is that the geometry is quite restrictive, reducing the number of ray paths that can be used. However, for NECESSArray, most of the events used are located outside the network, leaving a significant number of reverse two-station ray paths to work with.

In total, 11642 reverse two-station (RTS) and reverse two-event (RTE) paths (Fig. 6) are used in this study. Of these, 11442 paths have reverse two-station geometry, which requires a station pair 


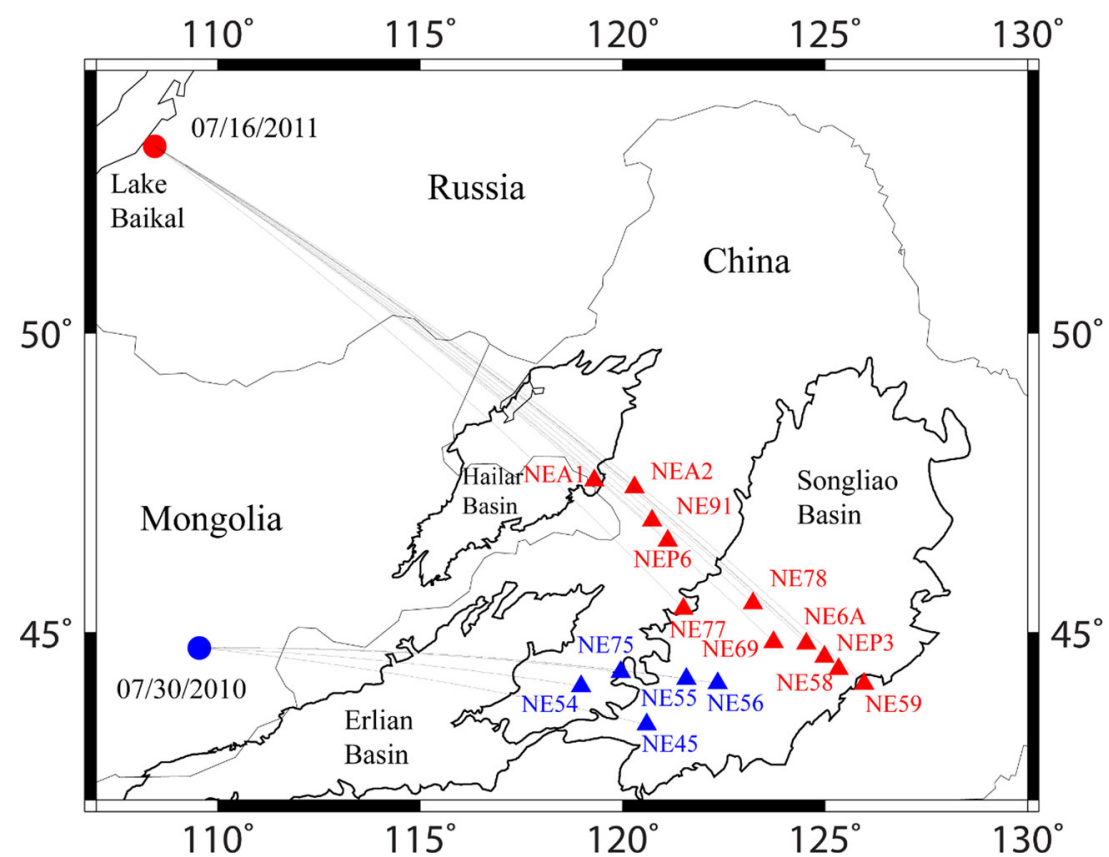

Figure 3. A map showing paths from the 2011 July 16 Lake Baikal event to stations ranging from the Great Xing'an Range to Songliao Basin (event and stations are coloured in red) and paths from the 2010 July 30 event from eastern Mongolia to stations ranging from the Great Xing'an Range to Songliao Basin (event and stations are coloured in blue).

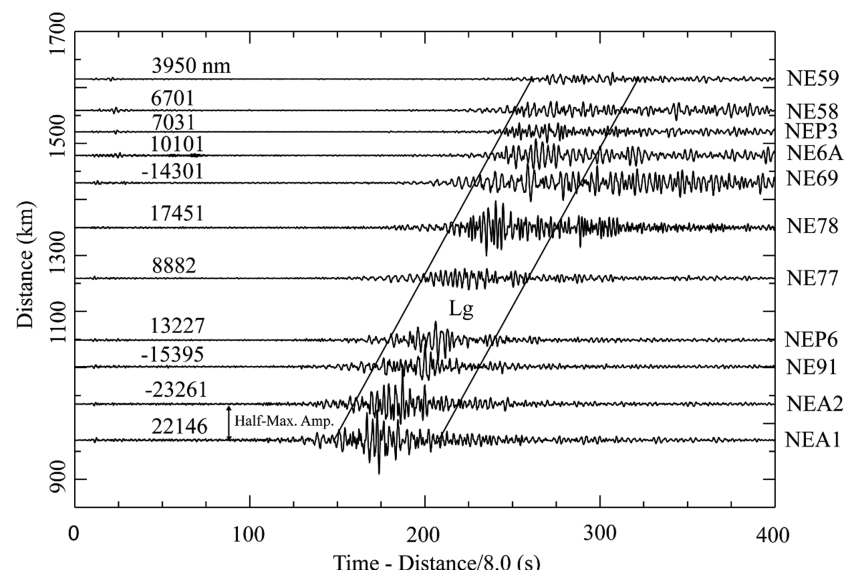

Figure 4. Seismograms from the 2011 July 16 earthquake from Lake Baikal. The vertical component ground displacements are displayed according to their epicentral distances in kilometres. The maximum half-amplitude is indicated in nanometres and the station names are listed on the right. The stations NE78, NE69 and NE6A in the Songliao Basin show amplification of amplitude relative to station NE77, which is located in the Great Xing' an Range and closer to the event.

between two events. The remaining 200 paths have reverse twoevent geometry, which requires an event pair between two stations. Ideally, the events and stations in both the RTE and RTS cases are arranged along a great circle path (Figs $7 \mathrm{a}$ and c); however, a more realistic arrangement allows the event locations, or in the case of the RTE method the station locations, to deviate from the great circle path (Figs $7 b$ and d). To minimize errors a maximum deviation of $15^{\circ}$ is allowed. This maximum was chosen based on a study by Der et al. (1984), where they determined that the forward scattered waves contained in $\mathrm{Lg}$ arrive at a station over a range of directions and that these waves are deflected from the great circle by a maximum angle of $15^{\circ}$. As suggested by Xie et al. (2004) and Bao et al. (2011), we assume that the error caused by these deviations

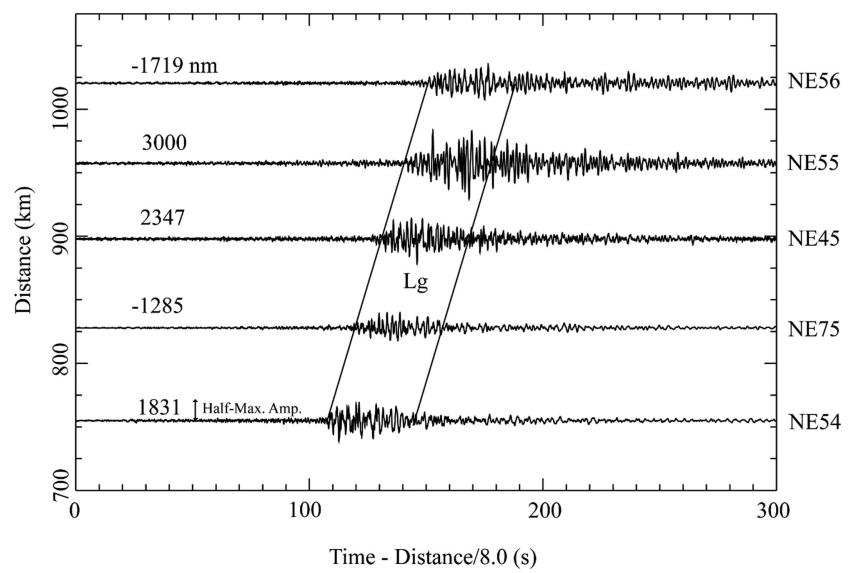

Figure 5. Seismograms from the 2010 July 30 earthquake from Mongolia. The vertical component ground displacements, the maximum half-amplitude and the station names are labelled in the same manner as in Fig. 4. The stations NE45, NE55 and NE56 in the Songliao Basin show amplification of amplitude relative to the closer stations NE75 and NE54.

in the forward scattered wave paths is similar to the error caused by the deviation of events or stations from the great circle path. Thus, a maximum deviation angle of $15^{\circ}$ should be appropriate.

The spectral amplitude measured at each station can be given as,

$A(f)=S(f) I(f) E(f) G(\Delta) \exp \left[\frac{-\pi f \Delta}{v Q(f)}\right]$,

where, $A(f)$ is the amplitude at a given frequency, $S(f)$ is the source response, $I(f)$ is the instrument response, $E(f)$ is the station site effect, $G(\Delta)$ is the geometrical spreading term, $v$ is the assumed average Lg group velocity of $3.5 \mathrm{~km} \mathrm{~s}^{-1}, f$ is the central frequency and $\Delta$ is the epicentral distance. In this study, we used a narrow band ranging from 0.5 to $1.5 \mathrm{~Hz}$ with a central frequency of $1 \mathrm{~Hz}$. 


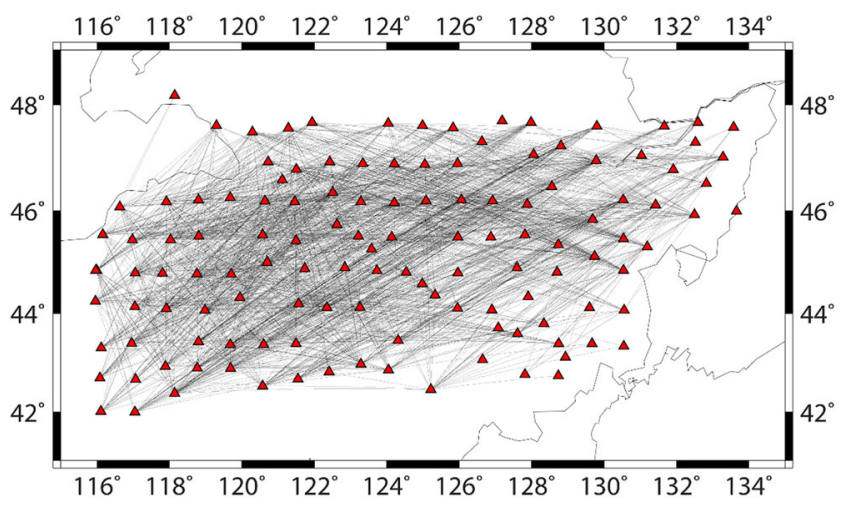

Figure 6. The ray path map showing 11642 reverse two-station/event paths used for this study. In total, 11442 paths have reverse two-station geometry and the other 200 paths have reverse two-event geometry. The red triangles show the locations of 127 NECESSArray stations.

(a)

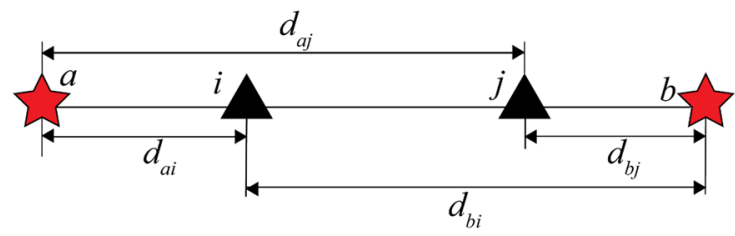

(b)

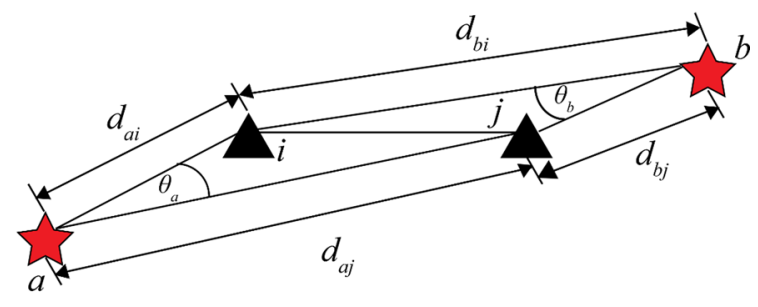

(c)

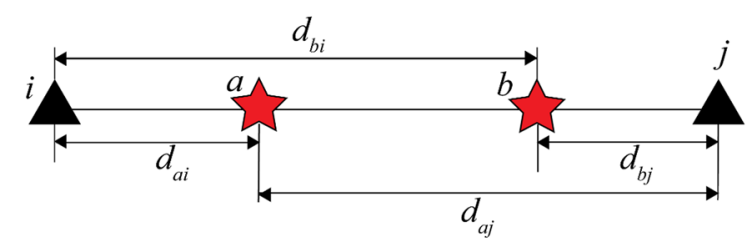

(d)

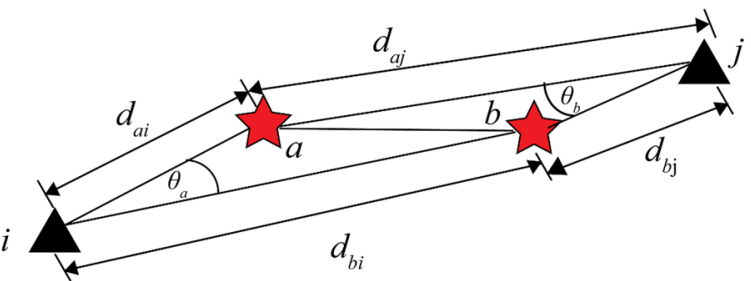

Figure 7. An illustration of reverse two-station and reverse two-event geometry. The black triangles $i$ and $j$ represent seismic stations and the red stars $a$ and $b$ represent earthquakes. The epicentral distances between the earthquakes $a$ and $b$ and the stations $i$ and $j$ are represented as $d_{a i}, d_{a j}$, $d_{b i}$ and $d_{b j}$, respectively. (a) The ideal geometry for the reverse two-station configuration. (b) The actual geometry for the reverse two-station configuration. (c) The ideal geometry for the reverse two-event configuration. (d) The actual geometry for the reverse two-event configuration. $\theta_{\mathrm{a}}$ and $\theta_{\mathrm{b}}$ are the subtended angles between earthquakes $a$ and $b$ for stations $i$ and $j$, respectively.

The geometric spreading term for the $\mathrm{Lg}$ waves is assumed to be in the form of,

$G(\Delta)=G_{0} \Delta^{-m}$, where $G_{0}$ is a constant (Chun et al. 1987; Yang 2002; Bao et al. 2011) and $m$ is the geometrical spreading term. In both methods event $a$ and event $b$ are used to calculate an amplitude ratio which is shown in eq. (3).

$$
\begin{aligned}
\frac{A_{a i}(f) A_{b j}(f)}{A_{a j}(f) A_{b i}(f)}= & \left(\frac{d_{a i} d_{b j}}{d_{a j} d_{b i}}\right)^{-m} \\
& \times \exp \left[\frac{\pi f}{v Q(f)}\left(d_{a j}-d_{a i}-d_{b j}+d_{b i}\right)\right] .
\end{aligned}
$$

This equation assumes a constant crustal velocity structure and constant $Q$ between stations $I$ and $j$ (RTS method) or between events $a$ and $b$ (RTE method). We can solve eq. (3) for the apparent attenuation factor $Q$ in terms of amplitudes and epicentral distances,

$$
\begin{aligned}
Q(f)_{\mathrm{path}}^{-1}= & v\left[\pi f \left(d_{a j}+d_{b i}-d_{a i}\right.\right. \\
& \left.\left.-d_{b j}\right)\right]^{-1} \ln \left[\frac{A_{a i}(f) A_{b j}(f)}{A_{a j}(f) A_{b i}(f)}\left(\frac{d_{a i} d_{b j}}{d_{a j} d_{b i}}\right)^{m}\right],
\end{aligned}
$$

where $A_{a j}, A_{a j}, A_{b i}$ and $A_{b j}$ are the spectral amplitudes recorded by stations $i$ and $j$ for events $a$ and $b$ and $d_{a i}, d_{b j}, d_{a j}$ and $d_{b i}$ are corresponding epicentral distances.

Geometrical spreading of the $\mathrm{Lg}$ wave is generally assumed to be 0.5 based on a theoretical study by Yang (2002). This corresponds to the spreading of a cylindrical wave front. We tested this by using our raw amplitude ratios from the station pairs to fit an equation in the form of

$\log _{10}\left(\frac{A_{a i}}{A_{a j}}\right)=\beta-m \log _{10}\left(\frac{d_{a i}}{d_{a j}}\right)-\alpha\left(d_{a i}-d_{a j}\right)$

for the constants $\beta, m$ and $\alpha$ with base 10 logarithms. The constant $\beta$ should be near zero but is included to account for a possible asymmetric distribution in station gains (i.e. station site effect). The constant $m$ represents the geometric spreading coefficient and $\alpha$ is the attenuation coefficient $[\alpha=\pi f \log e / v Q(f)]$. We found a geometric spreading coefficient of 0.36 with 95 per cent confidence bounds of $0.28-0.43$ and a gain $(\beta)$ of 0.026 magnitude units with 95 per cent confidence bounds of $0.0123-0.0398$. Average $Q_{\mathrm{o}}$ is calculated from the attenuation coefficient and is found to be 397 with 95 per cent confidence bounds of 378-409. For comparison, we constrain the spreading coefficient $m$ equal to 0.5 , a value that is often assumed for $\mathrm{Lg}$, and find a gain value of 0.050 with bounds of 0.036-0.064 magnitude units and a $Q_{0}$ value of 306 with bounds of 297-310. This is an increase in average $Q_{0}$ of 91 compared to the unconstrained result. This is a minor bias and does not affect the tomography patterns.

In order to see if our new results are significant, an $F$-test is performed. With a 95 per cent confidence level it is found that changing the spreading coefficient to 0.36 is significant, as is the change in the gain from the assumed $0-0.028$ magnitude units. It likely represents a ray path bias due to unequal azimuth distribution of ray paths that causes some stations to be used more than others and their gains are overemphasized. While non-zero, this is a relatively small number and can be ignored.

The data are processed by first filtering the vertical seismograms using seismic analysis code (SAC) with a two-pass, three-pole recursive Butterworth filter with corners at 0.2 and $5 \mathrm{~Hz}$. The $\mathrm{Lg}$ wave train group velocity window is set at $0.6 \mathrm{~km} \mathrm{~s}^{-1}$, where the beginning of the window is visually picked. This window should include as little of the beginning of the Rayleigh wave or Sn coda as possible. In cases where the $\mathrm{Lg}$ phase is blocked by oceanic crust the seismograms are not used. Pn arrival times are also picked in order to define the $20 \mathrm{~s}$ pre-Pn ambient noise window. The $\mathrm{Lg}$ and pre-Pn spectra are calculated based on these windows and then 


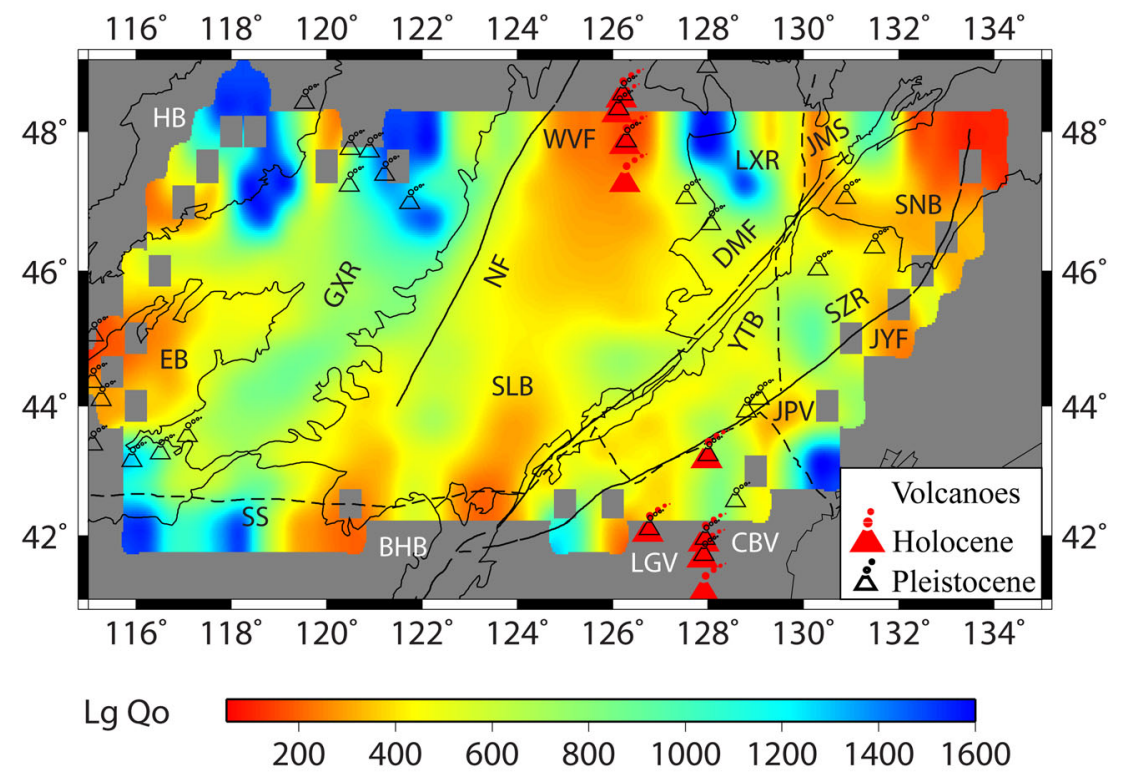

Figure 8. Map of $\operatorname{Lg} Q_{\mathrm{o}}$ in NE China. The abbreviations of the names of mountains, basins, sutures and faults are the same as in Fig. 1. Black lines indicate major active faults. Blue represents high $Q_{\mathrm{o}}$ (low attenuation) regions and red represents low $Q_{\mathrm{o}}$ (high attenuation) regions. High $Q_{\mathrm{o}}$ regions are mainly found in the mountains. Low $Q_{\mathrm{o}}$ regions are associated with Quaternary volcanic fields and sedimentary basins.

the instrument responses are removed. The signal-to-noise ratio (SNR) is calculated by dividing the Lg spectra by the pre-Pn spectra. Records with an average SNR below 2.0 are removed since these data are overwhelmed by noise. In this study we used the geometric spreading value of 0.36 that we calculated instead of the commonly assumed value of 0.5 . Once the spectra are obtained, the interstation

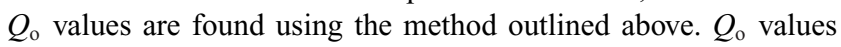
above 5000 , below 10 or with an error ratio greater than 0.6 are rejected. The error ratio is defined as the error in $Q_{0}$ divided by $Q_{\mathrm{o}}$, where the error is one standard deviation.

\section{RESULTS}

Extensive ray path coverage was obtained throughout NE China as shown in Fig. 6. Regions of high $Q_{0}$ in the $1 \mathrm{~Hz} \mathrm{Lg}$ attenuation model (Fig. 8) appear to correspond with the Great Xing'an Range, Lesser Xing'an Range and the Songen-Zhangguangcai Range. On average, $\operatorname{Lg} Q_{0}$ is found to be $\sim 900-1000$ in these mountain ranges. Southcentral and easternmost sections of the Songliao Basin show

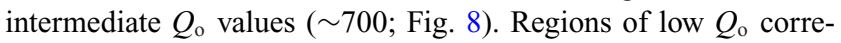
spond with basins such as the Erlian Basin, Sanjiang Basin and the northern and southern sections of the Songliao Basin. $\operatorname{Lg} Q_{0}$ ranges from $\sim 200$ to 400 in these high attenuation areas (Fig. 8). The Holocene age Wudalianchi volcanic field, which partially lies within the northern Songliao Basin, and the Pleistocene age volcanoes within the Sanjiang Basin also show low $Q_{0}$ regions (Fig. 8). Finally, Jingpuhi, a Quaternary volcanic field located along the southeastern edge of our area of study, shows a low $Q_{\text {o value of }}$ about 400 (Fig. 8).

In order to determine the resolution achieved by this ray path coverage, checkerboard models with \pm 15 per cent random noise were generated with $2^{\circ} \times 2^{\circ}, 1.5^{\circ} \times 1.5^{\circ}$ and $1^{\circ} \times 1^{\circ}$ cell sizes (Fig. 9). Only $2^{\circ} \times 2^{\circ}$ resolution is successfully recovered. There is a small amount of smearing even in the $2^{\circ} \times 2^{\circ}$ case, particularly along the edges of our area of study and in the southeastern area near the Changbaishan volcanic field where there was little instru- mentation. Ray paths crossing the Sea of Japan show a complete blockage of Lg (Rapine et al. 1997; Furumura \& Kennett 2001). Weak Sn with low amplitude and little coda are seen in the vertical component seismograms, therefore contamination of the Lg phase by $\mathrm{Sn}$ is considered minor.

\section{DISCUSSION}

Several correlations can be made when we compare our results to previous studies and known geological structures. First we compare our map with heat flow data collected from a limited number of wells in a study by Wang (2001). In a recent study Wang \& Cheng (2012) found high heat flow values of $\sim 70 \mathrm{mWm}^{-2}$ within the Songliao Basin, which corresponds to an estimated high temperature of about $600{ }^{\circ} \mathrm{C}$ at the Moho. Although regions of high heat flow ( $>70$ $\mathrm{mW} \mathrm{m}{ }^{-2}$ ) show low $Q_{0}$ values (>800; Fig. 10 ) there is insufficient heat flow data to state that heat flow is the sole cause of these values.

We also compared our results to a sediment thickness map (Fig. 11) based on a global model made by Laske and Masters (1997). The map shows that the deepest sediments, about $7 \mathrm{~km}$ deep, are found in the centre of the Songliao Basin near Daqing (Fig. 11). Regions with very thin $(<1 \mathrm{~km})$ or no sediments tend to show high $Q_{\text {o values }}(>800$; Fig. 12$)$ while areas with thicker sediments tend to show low $Q_{\mathrm{o}}$ values, but as is the case with heat flow, we cannot claim that thick sediments are the only cause for

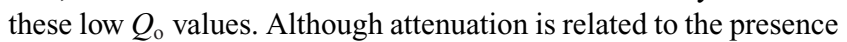
of thick sediments, it is not directly tied to the basin depths. The high attenuation in the southern part of the Songliao Basin (Fig. 8) could be partially due in part to the Late Cenozoic rifts associated with extension of the North China Craton and the Bohai Basin. Low $Q_{\text {o }}$ seen in the northern part of the basin may be due to the presence of the recently active Wudalianchi volcanic field.

The Erlian, Hailar and Sanjiang Basins contain only shallow sedimentary layers, about $\sim 1 \mathrm{~km}$ in the Erlian Basin and $\sim 1-2$ $\mathrm{km}$ in the Hailar Basin (Fig. 11). Again, a more likely explanation for the high attenuation seen in the Erlian and Sanjiang Basins 

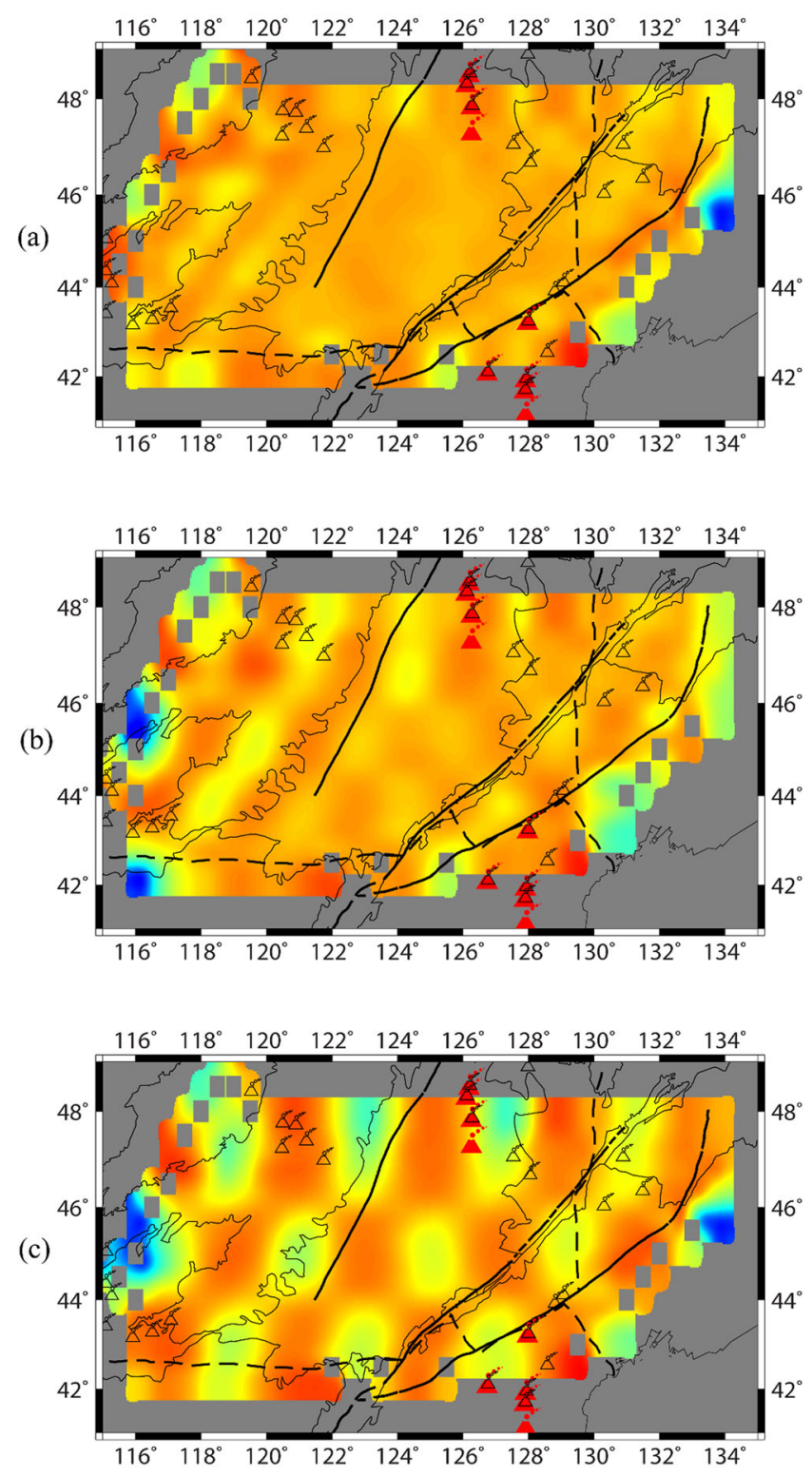

Figure 9. Resolution tests for $\operatorname{Lg} Q_{0}$. The same ray paths and damping factor that were used to produce the $\operatorname{Lg} Q_{\mathrm{o}}$ image are used in the resolution tests. (a) $1^{\circ} \times 1^{\circ}$ resolution test image. Note that details in the Songliao Basin and the Great Xing' an Range cannot be resolved. (b) $1.5^{\circ} \times 1.5^{\circ}$ resolution test image. Some of the features in the Songliao Basin and the Great Xing'an Range can be resolved. (c) $2^{\circ} \times 2^{\circ}$ resolution test image. With the exception of the edges, most of the attenuation anomalies are resolved.

is the collective effect of the presence of Pleistocene volcanism, unconsolidated sediments and high heat flow.

We compare low $Q_{\text {o }}$ areas to the presence of volcanism. Pleistocene volcanoes along the edge of the Sanjiang Basin appear to correspond to the low $Q_{\mathrm{o}}$ values seen in that region. The Jingpuhi volcanoes (Fig. 8) in the southeast are also located in a region of low $Q_{0}$. The Changbaishan volcanic field is also shown on our map (Fig. 8). However, a lack of data in this region does not allow us to draw any conclusions at this time. Overall, we observe that Holocene volcanoes have a greater effect on $\mathrm{Lg}$ attenuation than Pleistocene volcanoes as shown in Fig. 13. The $Q_{\mathrm{o}}$ values for Pleistocene volcanoes vary from $\sim 100$ to 1300 (Fig. 13a) while

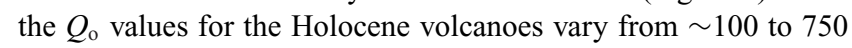

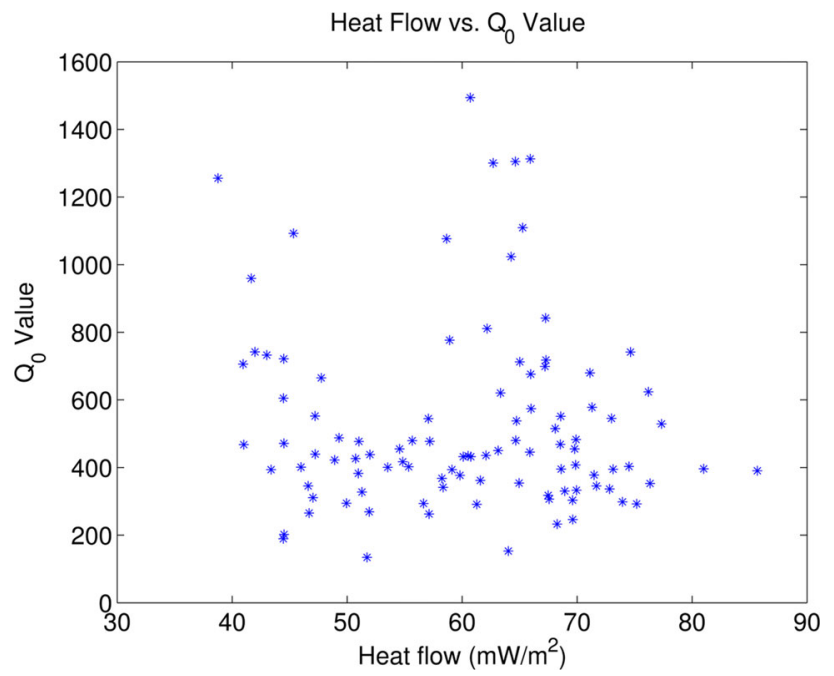

Figure 10. Scatter plot of $Q_{\mathrm{o}}$ versus interpolated heat flow value. The $Q_{\mathrm{o}}$ value at each integer degree latitude-longitude intersection point is plotted against the interpolated heat flow value at the respective point. The heat flow values are interpolated using a limited number of values assimilated from the Global Heat Flow Database for China. Regions with high heat flow $\left(<70 \mathrm{~mW} \mathrm{~m}^{-2}\right)$ tend to show low $Q_{\mathrm{o}}(<800)$.

(Fig. 13b). Therefore we can conclude that younger volcanoes have a more dominant influence on $\mathrm{Lg}$ attenuation.

We compare our study to a recent study of anisotropic Rayleigh wave phase velocity beneath NE China, which shows significant lateral variation of crustal velocities (Tian et al. 2013). We specifically looked at the 20 and $25 \mathrm{~s}$ Rayleigh wave phase velocity images, which sample the middle crust. The 20 and 25 s Rayleigh waves have a higher phase velocity beneath the Great Xing'an Range, the Lesser Xing'an Range and the northern part of the SongenZhangguangcai Range. Lower phase velocities were found beneath the rifted Songliao Basin. Thus, regions of high $Q_{0}$ appear to correspond with high velocities and regions of low $Q_{0}$ appear to correspond with low velocities. Regions of low phase velocities were also found beneath the Changbaishan volcanic field and Mongolia in Tian et al.'s (2013) study.

We also compare our study to the previous Lg attenuation study done by Zhao et al. (2010), where they used $1720 \mathrm{Lg}$ wave spectra derived from 20 stations and 125 earthquakes from 1995 October to 2007 August. They found high attenuation areas with $Q_{0}$ values ranging from $\sim 10$ to 300 corresponding to the Erlian and Sanjiang Basins as well as the northern and southern Songliao Basin. In the mountainous areas $Q_{0}$ values of $\sim 400-900$ were found but there was significant variation in $Q$ with frequency. Our regional patterns of attenuation in these regions are consistent with those found by Zhao et al. (2010). However, the $\operatorname{Lg} Q_{\text {o }}$ values found by Zhao et al. (2010) are consistently lower by $\sim 200-300$ than those we found in our study. The difference between our values arises because our tomographic method inverted for $1 / Q_{\mathrm{o}}$, while Zhao et al. (2010) inverted for $Q_{0}$. If the $Q_{0}$ value distribution does not contain high $Q_{\mathrm{o}}$ values in a mapped region, the inversion will yield a smaller average $Q_{0}$ value. With the exception of these differences, the gross attenuation features of the two models are consistent.

Overall, the main characteristics of Lg attenuation in NE China are that low $Q_{\text {o }}$ regions occur within basins that contain unconsolidated sediments or have experienced Quaternary volcanic activity and beneath Quaternary volcanic fields located outside of basins. High $Q_{\mathrm{o}}$ regions are associated with mountains and granitic regions that were not greatly affected by Cenozoic tectonics. 


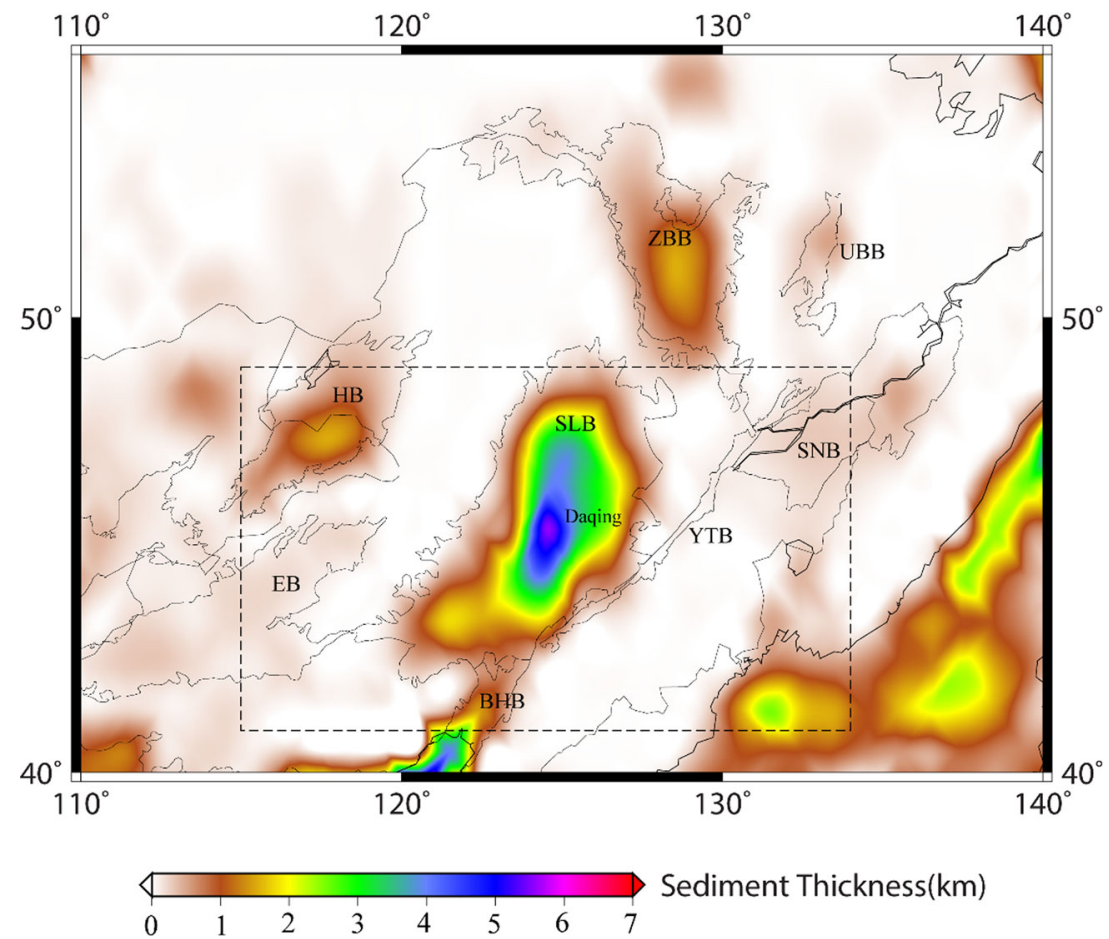

Figure 11. Sediment thickness map for NE China based on the global digital map of Laske \& Masters (1997). The abbreviations of the names of the basins are: BHB (Bohai Basin), EB (Erlian Basin), HB (Hailar Basin), SLB (Songliao Basin), ZBB (Zeya-Bureya Basin), UBB (Upper Bureya Basin), SNB (Sanjiang Basin) and YTB (Yitong Basin). The thickest sediments ( 6-7 km) are found close to Daqing in the Songliao Basin.

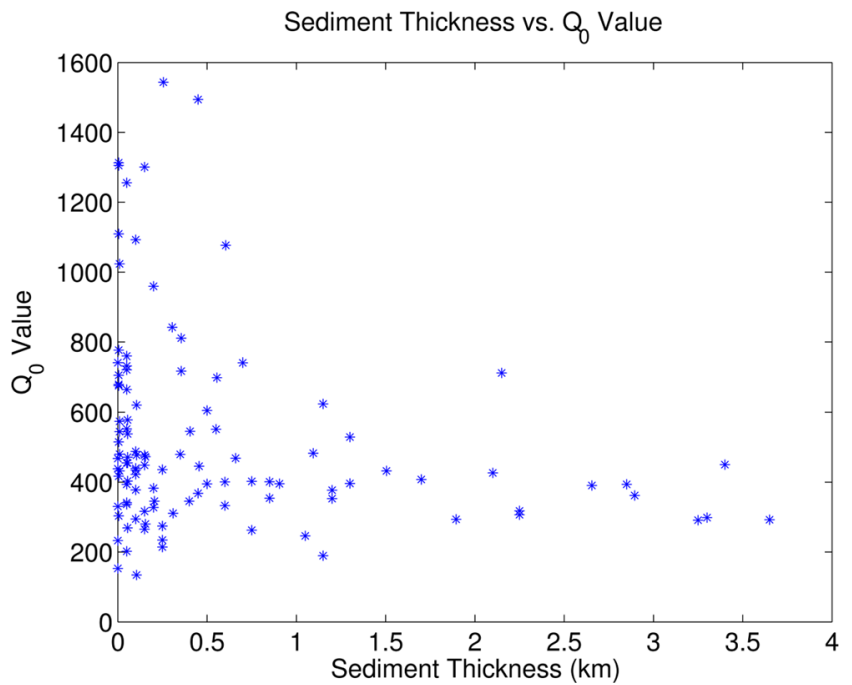

Figure 12. Scatter plot of interpolated sediment thickness versus $Q_{0}$. The $Q_{\mathrm{o}}$ value at each integer degree latitude-longitude intersection point is plotted against the sediment thickness at the respective point. Regions with high $Q_{\mathrm{o}}$ $(>800)$ have very thin $(>1 \mathrm{~km})$ or no sediments.

\section{CONCLUSION}

The RTM was used to measure $\operatorname{Lg} Q_{\mathrm{o}}$ in NE China using an extensive data set collected by the NECESSArray. The advantage of this method is that it eliminates the source and site terms completely. Our comprehensive $\operatorname{Lg} Q_{\mathrm{o}}$ image can resolve features of about $2^{\circ}$ $\times 2^{\circ}$ overall, with the best resolution being found in the Songliao Basin and surrounding regions. To the first order, strong lateral variation of $\mathrm{Lg}$ attenuation throughout NE China is correlated with Late
Cenozoic tectonics. Areas of low attenuation were found to correspond to high Rayleigh wave phase velocities while areas of high attenuation correlated well with regions of low Rayleigh wave phase velocities. Highly attenuating regions are found to be mainly associated with areas affected by Holocene volcanism. Unconsolidated thick sediments also attenuate Lg waves in the southern Songliao and Erlian Basins, but this effect seems to be less drastic than the effects due to the Holocene volcanoes.

\section{ACKNOWLEDGEMENTS}

We would like to thank Xueyang Bao, William Scott Phillips and Jiakang Xie for their insights on modelling $\mathrm{Lg}$ attenuation and contributions in coding the programs used in this study. We thank editor Gabi Laske and the two anonymous reviewers for their constructive comments, which improved this manuscript immensely. We would also like to thank the dedicated international team from China, Japan and the USA who collected the NECESSArray waveforms used in this study. Instruments and critical field and data assistance were provided by the PASSCAL facility of the Incorporated Research Institutions for Seismology (IRIS) through the PASSCAL Instrument Center at New Mexico Tech and also instrument pools from the Peking University and University of Tokyo. Finally, we would like to thank Paul Wessel and Walter H.F. Smith for the use of the Generic Mapping Tools (GMT) software, Lawrence Livermore for the use of their Seismic Analysis Code (SAC), the National Geophysical Data Center of NOAA for making the Etopo1 global relief map freely available, Fugro Robertson, Ltd. for making the basin classification database freely available through AAPG, Global Heat Flow Database of the International Heat flow Commission for collecting the heat flow data in China, Oliver Woodford for his export_figmatlab ${ }^{\circledR}$ code used to plot Figs 10, 12 and 13 and David 

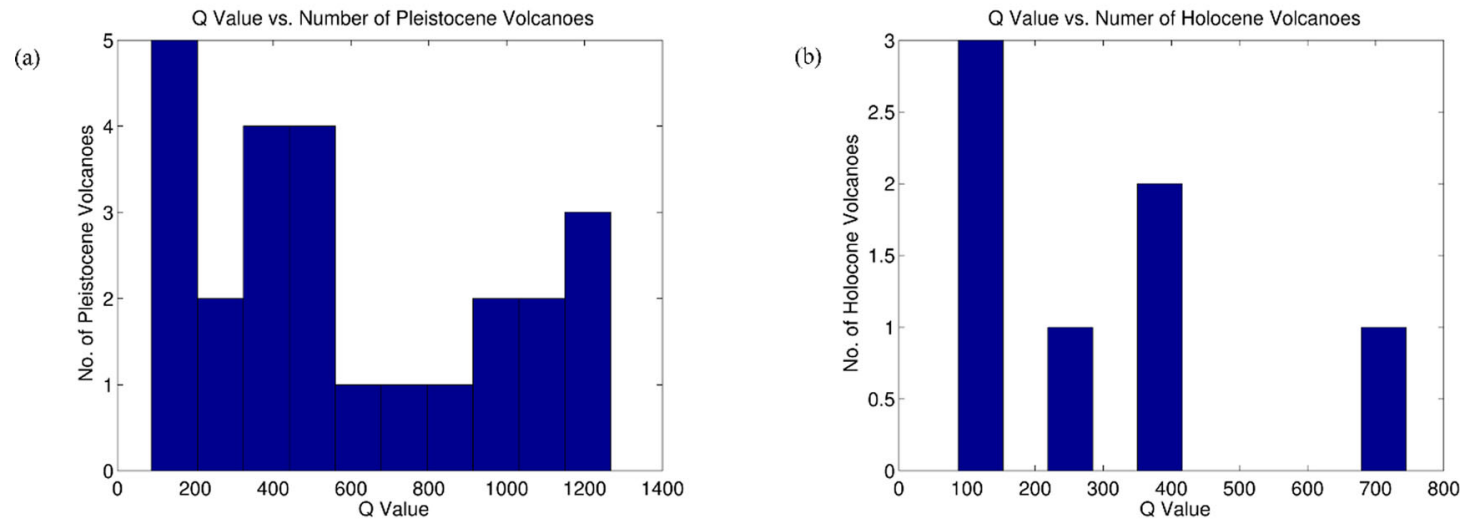

Figure 13. Histograms of $Q_{\mathrm{o}}$ values at each Pleistocene and Holocene volcano in the $\operatorname{Lg} Q_{\mathrm{o}}$ map. (a) $Q_{\mathrm{o}}$ value of each Pleistocence volcano. (b) $Q_{\mathrm{o}}$ value of each Holocene volcano. The $Q_{\mathrm{o}}$ values of Holocene volcanoes vary from $\sim 100$ to 750 while the $Q_{\mathrm{o}}$ values of Pleistocene volcanoes vary from $\sim 100$ to 1200 . The younger volcanoes tend to have a greater effect on the $\mathrm{Lg}$ attenuation than the older volcanoes.

Ljung Madison for the colour schemes used for Figs 2 and 11. NECESSArray data are openly available from the IRIS Data Management System under experiment code YP 2009-2011. New Mexico State University is supported under NSF EAR-0608629, U.S. Air Force Research Laboratory contract No. FA9453-12-C-0235 and Los Alamos National Security Subcontract No. 218475.

\section{REFERENCES}

Bao, X., Sandvol, E., Ni, J., Hearn, T., Chen, Y.J. \& Shen, Y., 2011. High resolution regional seismic attenuation tomography in eastern Tibetan Plateau and adjacent regions, Geophys. Res. Lett., 38, L16304, doi:10.1029/2011GL048012.

Bao, X., Sandvol, E., Chen, Y.J., Ni, J., Hearn, T. \& Shen, Y., 2012. Azimuthal anisotropy of $\mathrm{Lg}$ attenuation in eastern Tibetan Plateau. J. geophys. Res., 117, B10309, doi:10.1029/2012JB009255.

Bouchon, M., 1982. The complete synthesis of seismic crustal phases at regional distances, J. geophys. Res., 87, 1735-1741.

Campillo, M., Gariel, J.C., Aki, K. \& Sanchez-Seema, F.J., 1989. Destructive strong ground motion in Mexico City: source, path, and site effects during great 1985 Michocan earthquake, Bull. seism. Soc. Am., 79, 1718-1735.

Chun, K.-Y., West, G.F., Kokoski, R.J. \& Samson, C., 1987. A novel technique for measuring $\mathrm{Lg}$ attenuation results from eastern Canada between 1 to $10 \mathrm{~Hz}$, Bull. seism. Soc. Am., 77, 398-419.

Der, Z., Marshall, M.E., O'Donnell, A. \& McElfresh, T.W., 1984. Spatial coherence structure and attenuation of the Lg phase, site effects, and interpretation of the Lg coda, Bull. seism. Soc. Am., 74, 1125-1148.

Furumura, T. \& Kennett, B.L.N., 2001. Variations in regional phase propagation in the area around Japan, Bull. seism. Soc. Am., 91, 667-682.

Gallegos, A., Ranasinghe, N., Ni, J. \& Sandvol, E., 2014. Lg attenuation in central and eastern United States as revealed by the EarthScope Transportable Array, Earth planet. Sci. Lett., 402, 187-196.

Hasegawa, H.S., 1985. Attenuation of $L g$ waves in the Canadian Shield, Bull. seism. Soc. Am., 75, 1569-1582.

Herrmann, R.B. \& Kijko, A., 1983. Modeling some empirical vertical component $L g$ relations, Bull. seism. Soc. Am., 73, 157-171.

Kiminami, K. \& Imaoka, T., 2013. Spatiotemporal variations of JurassicCretaceous magmatism in eastern Asia (Tan-Lu Fault to SW Japan): evidence for flat-slab subduction and slab rollback, Terra Nova, 25, doi:10.1111/ter.12051.

Knopoff, L., Schwab, F. \& Kausel, E., 1973. Interpretation of Lg, Geophys. J. R. astr. Soc., 33, 389-404.

Laske, G. \& Masters, G., 1997. A global digital map of sediment thickness, EOS, Trans. Am. geophys. Un., 78, F483.

Li, S.Q., Chen, F., Siebel, W., Wu, J.D., Zhu, X.Y, Shan, X.L. \& Sun, X.M., 2012. Late Mesozoic tectonic evolution of the Songliao Basin, NE China: evidence from detrital zircon ages and Sr-Ndisotopes, Gondwana Res., 22, 943-955.

Liu, J., Han, J. \& Fyfe, W.S., 2001. Cenozoic episodic volcanism and continental rifting in northeast China and possible link to Japan Sea development as revealed from K-Ar geochronology, Tectonophysics, 339, 385-401.

McNamara, D.E., Owens, T.J. \& Walter, W.R., 1996. Propagation characteristics of Lg across the Tibetan Plateau, Bull. seism. Soc. Am., 86, 457-469.

Ni, J. \& Barazangi, M., 1983. High-frequency seismic wave propagation beneath the Indian Shield, Himalayan Arc, Tibetan Plateau and surrounding regions: high uppermost mantle velocities and efficient $S_{n}$ propagation beneath Tibet, Geophys. J. Int., 72, 665-689.

Oliver, J., Ewing, M. \& Press, F., 1955. Crustal structure of the Arctic regions from the Lg Phase, Geol. Soc. Am. Bull., 66, 1063-1074.

Pratt, T.L., Brocher, T.M., Weaver, C.S., Creager, K.C., Snelson, C.M., Crosson, R.C., Miller, K.C. \& Trehu, A.M., 2003. Amplification of seismic waves by the Seattle Basin, Washington State, Bull. seism. Soc. Am., 93, 533-545.

Phillips, W.S. \& Stead, R.J., 2008. Attenuation of $\mathrm{Lg}$ in the western US using the USArray, Geophys. Res. Lett., 35, L07307, doi:10.1029/2007GL032926.

Rapine, R.R., Ni, J.F. \& Hearn, T.M., 1997. Regional Wave Propagation in China and Its Surrounding regions, Bull. seism. Soc. Am., 87, 1622-1636.

Ruzaikin, A.I., Nersesov, I.L., Khalturin, V.I. \& Molnar, P., 1977. Propgation of $\mathrm{Lg}$ and Latteral variations in crustal structure in Asia, J. geophys. Res., 82, 307-316.

Singh, S. \& Herrmann, R.B., 1983. Regionalization of crustal coda Q in the continental United States, J. geophys. Res., 88, 527-538.

Sengör, A.M.C., Natal'in, B.A. \& Burtman, V.S., 1993. Evolution of the Altaid tectonic collage and Palaeozoic crustal growth in Eurasia, Nature, 364, 299-307.

Sun, M.D., Chen, H.L., Zhang, F.Q., Wilde, S.A., Dong, C.W. \& Yang, S.F., 2012. A 100 Ma bimodal composite dyke complex in the Jiamusi Block, NE China: indication for lithospheric extension driven by Paleo-Pacific roll-back, Lithos, 162-163, 317-330.

Tian, Y., Legendre, C.P., Zhao, L., Wu, M., Lebedev, S., Chen, Q. \& Ning, J., 2013. Anisotropic Rayleigh-wave phase-velocity maps beneath northeastern China, Presented at 2013 Fall Meeting, AGU, San Francisco, December 15-19.

Trujillo, A., 2013. Tectonics and Lg attenuation of Northeast China, MS thesis, Department of Physics, New Mexico State University, Las Cruces, New Mexico, USA, 92 pp.

Wang, Y., 2001. Heat flow pattren and lateral variation of lithosphere strength in China mainland: constraints on active deformation, Phys. Earth planet. Inter, 126, 121-146.

Wang, Y. \& Cheng, S.-H., 2012. Lithospheric thermal structure and rheology of the eastern China, J. Asian Earth Sci., 47, 51-63. 
Windley, B.F., Alexeiev, D., Xiao, W., Kröner, A. \& Badarch, G., 2007. Tectonic models for accretion of the Central Asian Orogenic Belt, $J$. Geol. Soc., Lond., 164, 31-47.

Xie, J., 2002. Lg Q in the eastern Tibetan Plateau, Bull. seism. Soc. Am., 92, 871-876.

Xie, J., Gok, R., Ni, J. \& Aoki, Y., 2004. Lateral variations of crustal seismic attenuation along The INDEPTH profiles in Tibet from Lg Q inversion, J. geophys. Res., 109, B10308, doi:10.1029/2004JB002988.

Xie, J.K. \& Mitchell, B.J., 1990. A back-projection method for imaging large-scale lateral variations of $\mathrm{Lg}$ coda $\mathrm{Q}$ with application to continental Africa, J. geophys. Res., 100, 161-181.

Yang, X., 2002. A numerical investigation of Lg geometrical spreading, Bull. seism. Soc. Am., 92, 3067-3079.

Zhang, J.H., Gao, S., Ge, W.C., Wu, F.Y., Yang, J.H., Wilde, S.A. \& Li, M., 2010. Geochronology of the Mesozoic volcanic rocks in the Great Xing' an Range, northeastern China: implications for subduction-induced delamination, Chem. Geol., 276, 144-165.

Zhao, L.-F., Xie, X.-B., Wang, W.-M., Zhang, J.-H. \& Yao, Z.-X., 2010. Seismic Lg-wave Q tomography in and around Northeast China, J. geophys. Res., 115, B08307, doi:10.1029/2009JB007157.

Zhou, J.B. \& Wilde, S., 2012. The crustal accretion history and tectonic evolution of the NE China segment of the Central Asian Orogenic Belt, Gondw. Res., 23, 1365-1377.
Zhou, Z.H., Mao, W. \& Lyckberg, P., 2012. Geochronology and isotopic geochemistry of the A-type granites from the Huanggang Sn-Fe deposit, southern Great Hinggan Range, NE China: implication for their origin and tectonic setting, J. Asian Earth Sci., 49, 272-286.

Zor, E., Sandvol, E., Xie, J., Turkelli, N., Mitchell, B., Gasanov, A.H. \& Yetirmishli, G., 2007. Crustal attenuation within the Turkish Plateau and surrounding regions, Bull. seism. Soc. Am., 97, 151-161.

\section{SUPPORTING INFORMATION}

Additional Supporting Information may be found in the online version of this article:

Appendix A Earthquake hypocentre parameters (http://gji. oxfordjournals.org/lookup/suppl/doi:10.1093/gji/ggu375/-/DC1).

Please note: Oxford University Press is not responsible for the content or functionality of any supporting materials supplied by the authors. Any queries (other than missing material) should be directed to the corresponding author for the article. 